\title{
Decreasing expander breast infection: A new drain care protocol
}

\author{
John D Murray MD FACS ${ }^{1,2}$, Eric T Elwood MD FACS ${ }^{1,2}$, Glyn E Jones MD FACS FRCS ${ }^{1,2}$, \\ Rebecca Barrick PA-C ${ }^{2}$, Jack Feng $\mathrm{PhD}^{3}$
}

JD Murray, ET Elwood, GE Jones, R Barrick, J Feng. Decreasing expander breast infection: A new drain care protocol. Can J Plast Surg 2009;17(1):17-21

BACKGROUND: Risk factors for expander reconstruction infection are well known. However, drain use as a risk factor for the development of infection is unclear.

OBJECTIVE: To review a simple method for drain use to help reduce rates of infection in expander breast reconstruction.

METHODS: Two hundred consecutive single-surgeon (JDM) immediate first-stage expander breast reconstructions were retrospectively reviewed. The records were reviewed for history and physical examination, intraoperative technique, perioperative management, adjuvant therapy, and outcome with respect to expander infection necessitating premature explantation within the first eight weeks. Infection was defined on clinical basis, with or without culture positivity. All expanders (Mentor, USA) were the same model (textured, port-integrated and biodimensional). Two consecutive series of reconstructions were then created. The first series included 177 reconstructions while the second series included 23 reconstructions. Unlike the first series, the second series introduced a protocol in which all reconstructions received mupirocin $2 \%$ cream to the drain sites and all drains were removed at the end of the first week. Additionally, in the second series, all expanders were secluded from direct in vivo contact with the closed suction drain either by the use of an intervening Alloderm sling (LifeCell Corporation, USA, 15 of 23 breasts) or by subdermally tunnelling the drain superficial to an adequate fatty subcutaneous layer (eight of 23 breasts).

RESULTS: Patients who developed infection in the first series and all patients in the second series shared statistically the same level of aggregate risk factors $(\mathrm{P}=0.531)$. The infection rate $(5.65 \%, 10$ infections in 177 breasts) in the first series was statistically greater than in the second series ( $0 \%, 0$ in 23 breasts, $\mathrm{P}=0.001)$.

CONCLUSIONS: The present study found that percutaneous closed suction drains do serve as an increased risk for expander infection. However, early results indicate that in vivo protection of the expander with Alloderm or subdermal tunnelling, topical antibiotic ointment use and early drain removal may significantly reduce expander infection.

Key Words: Adult; Alloderm; Breast expander; Breast implants, Breast neoplasms; Breast reconstruction; Closed suction drains; Combined modality therapy; Drains; Female; Humans; Infection; Mammaplasty; Mastectomy; Mupirocin; Tissue expansion devices

Two-stage expander breast reconstruction remains one of the most widely used techniques for postmastectomy reconstruction. Infection of the expander most frequently requires explantation for timely infection clearance. Premature expander explantation delays not only reconstructive efforts, but may also delay the commencement or continuance of

\section{Réduction de l'infection des expanseurs mammaires : Nouveau protocole de drainage}

HISTORIQUE : On connaît bien les facteurs de risque associés à l'infection des expanseurs lors de reconstructions mammaires. Toutefois, on ignore si l'utilisation de drains pose un risque à cet égard.

OBJECTIF : Passer en revue une méthode simple de pose de drain afin de réduire les taux d'infection lors de reconstructions mammaires avec expanseurs.

MÉTHODE : Les auteurs ont analysé de manière rétrospective la première étape de deux cents reconstructions mammaires consécutives avec expanseurs, réalisées par un seul et même chirurgien (JDM). Les auteurs ont tenu compte des antécédents, du résultat de l'examen physique, de la technique opératoire, de la prise en charge périopératoire, du traitement adjuvant et de l'issue de la chirurgie en ce qui a trait aux infections des expanseurs ayant pu forcer leur retrait prématuré au cours des huit premières semaines. L'infection a été définie sur une base clinique, indépendamment des résultats des cultures. Tous les expanseurs (Mentor, USA) étaient du même modèle (texturé, à valve auto-obturante et biodimensionnel). Deux séries de reconstructions consécutives ont ensuite été créées. La première série incluait 177 reconstructions, tandis que la seconde en comptait 23. Contrairement à la première série, la seconde prévoyait l'utilisation d'un protocole en vertu duquel de la mupirocine en crème à $2 \%$ était appliquée au niveau du point d'insertion des drains pour toutes les reconstructions et tous les drains étaient retirés à la fin de la première semaine. De plus, dans la seconde série, tous les expanseurs ont été protégés d'un contact direct in vivo avec le système de drainage, soit par l'utilisation d'un dispositif Alloderm (LifeCell Corporation, USA, 15 seins sur 23), soit par l'insertion sous-dermique du drain, à la surface d'une couche sous-cutanée adipeuse adéquate ( 8 seins sur 23 ).

RÉSULTATS : Les patientes qui ont développé une infection dans la première série et toutes les patientes de la seconde série présentaient le même degré statistique de facteurs de risque regroupés $(\mathrm{p}=0,531)$. Le taux d'infection a été statistiquement plus levé dans la première série $(5,65 \%, 10$ infections sur 177 seins) que dans la seconde ( $0 \%, 0$ sur 23 seins, $\mathrm{p}=0,001)$.

CONCLUSION : La présente étude a permis de conclure que les drains d'aspiration percutanés contribuent à l'accroissement du risque d'infection de l'expanseur. Toutefois, selon des résultats préliminaires, la protection in vivo de l'expanseur au moyen d'Alloderm ou du positionnement sousdermique du drain, en plus de l'application topique d'un onguent antibiotique et du retrait précoce du drain, peut réduire significativement l'infection des expanseurs.

adjuvant postmastectomy chemotherapy and/or radiation therapy. Premature expander explantation may create psychological deflation, potentially leading to avoidance of any further reconstructive efforts. Additionally, the economic cost of the clearance of the expander-related infection as well as occupational loss of wages dramatically increases the cost of the reconstruction.

${ }^{1}$ Division of Plastic Surgery, University of Illinois College of Medicine at Peoria; ${ }^{2}$ Illinois Plastic Surgery; ${ }^{3}$ Department of Industrial and

Manufacturing Engineering and Technology, Bradley University, Peoria, Illinois, USA

Institution at which the work originated: University of Illinois College of Medicine at Peoria

Correspondence: Dr John D Murray, 1001 Main Street, Suite 300, Peoria, Illinois 61606-2037, USA. Telephone 309-495-0250,

fax 309-676-6545, e-mail murray1@uic.edu 


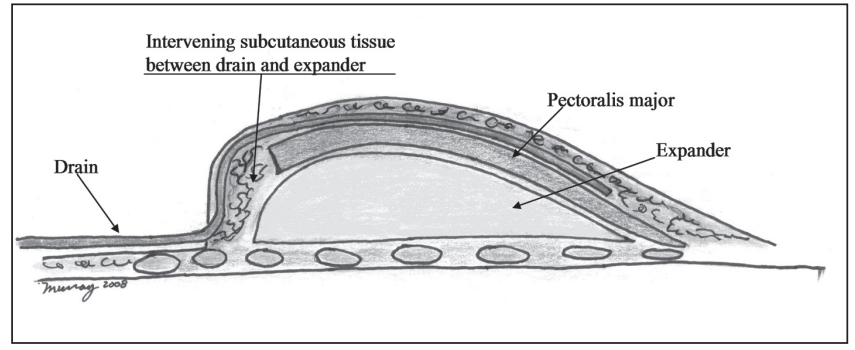

Figure 1) Subdermal tunnelling of drain (cross section)

While risk factors of surgical site infection, including diabetes, obesity and smoking, are well known, the risk related to the use of a closed suction drain in expander breast reconstruction is not well known. Over the past 40 years, many different case reports and studies have examined the use of closed suction drains and their relationship to infection across many surgical specialties. However, infection as related to prosthetic breast reconstruction, with or without mention of drain use, is varied in the literature. The present paper reviews our experience with infection related to expander breast reconstruction and the benefits afforded by expander seclusion from the drain, early drain removal and use topical antibiotic ointment.

\section{Patient population}

\section{METHODS}

One hundred thirty-nine women presented for breast reconstruction between July 1, 2003, and March 1, 2008. Seventynine women underwent a unilateral therapeutic mastectomy while 60 women underwent a unilateral therapeutic mastectomy as well as a contralateral prophylactic mastectomy. A thorough history and physical examination was completed on each woman, with noted risk factors of obesity (body mass index [BMI] $30 \mathrm{~kg} / \mathrm{m}^{2}$ or higher), current smoking, diabetes, and the use of preoperative or postoperative chemotherapy being recorded. All patients wished to undergo two-stage breast reconstruction with the initial placement of a breast expander, which would then be intervally exchanged for a saline implant by the senior author (JDM). Although all patients were followed for at least six months, 'early infection' was defined as expander infection occurring within eight weeks following expander placement. No patients developed expander breast infection beyond this eight-week period. Patients were dropped from further data inclusion if an expander was removed due to infection. Additionally, while all patients were followed for the first six months, not all patients had undergone second-stage reconstruction at the time of study submission.

\section{Operative technique for all 200 reconstructions}

The mastectomy and immediate expander reconstruction used basic strict sterile techniques. All patients washed their chest and breasts with chlorhexidine gluconate $4 \%$ solution at home before presenting to the hospital. All patients received preoperative antibiotics within $60 \mathrm{~min}$ of the start time and antibiotics were redosed intraoperatively according to schedule, with all patients receiving prophylactic oral antibiotics until the drains were removed and the drain sites healed. Intraoperatively, the mastectomy flaps and chest wall were liberally irrigated with saline combined with bacitracin and

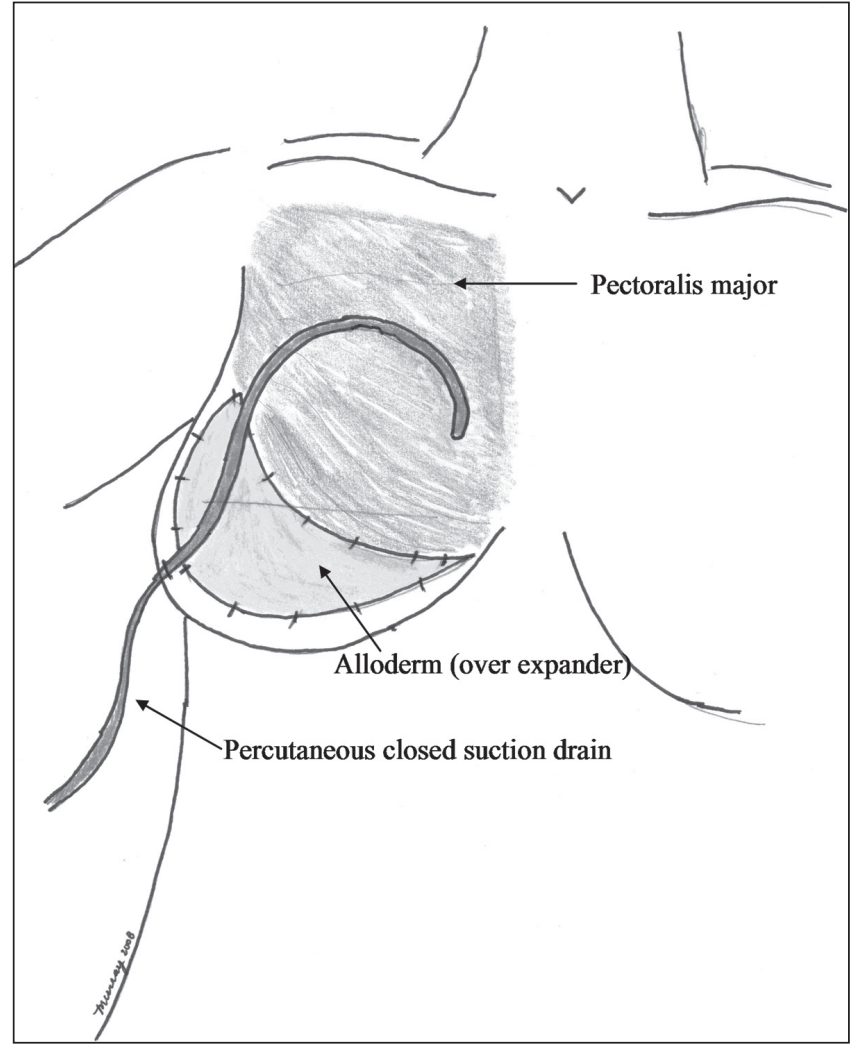

Figure 2) Drain draped over Alloderm (LifeCell Corporation, USA) and pectoralis major muscle.

kanamycin. After the surgeon's gloves were washed of debris, a Mentor (USA) style 6200 textured expander was placed in the subpectoral position without the expander touching the patient's skin or surgical towels. In all cases, the pectoralis major muscle did not cover the inferior portion of the expander, thus leaving partial muscular coverage. Injectable saline was infused to each expander to the tolerance of skin tension. A single $15 \mathrm{Fr}$, percutaneous, fully fluted hubless closed suction drain with an antireflux valve (Ethicon, USA) was placed just before incision closure through the lateral inframammary fold.

Additional operative technique for the last 23 reconstructions The last 23 reconstructions specifically secluded the drain from direct in vivo contact with the expander. In this second series, the expander was secluded from direct in vivo contact from the percutaneous drain by either tunnelling the percutaneous drain in the subdermal space, superficial to an adequate subcutaneous fatty layer, or by draping the drain over the intervening inferior Alloderm (LifeCell Corporation, USA) sling. If adequate subcutaneous fat was present on the inferior mastectomy flap, the percutaneous drain was tunnelled from the level of the lateral inframammary fold superiorly in the subdermal space, over the expander and then over the pectoralis major muscle (Figure 1). Doing so protected the expander from the drain with adequate intervening subcutaneous fat (eight of the last 23 reconstructions). However, in the remaining 15 of these last 23 reconstructions, Alloderm was sutured from the pectoralis down to the inframammary fold and over the expander with the use of a running polydiaxanone suture (Ethicon, USA) (Figure 2). The closed suction drain was positioned from its percutaneous 
TABLE 1

\section{Summary of both series for first stage breast reconstruction}

\begin{tabular}{l}
\hline Series 1 \\
\hline 121 women, 177 breast reconstructions \\
Technique \\
Percutaneous subcutaneous drain in contact with expander \\
Drain removal until output less than $25 \mathrm{~mL}$ for 2 days \\
Follow-up 8 weeks \\
Series 2 \\
\hline 18 women, 23 breast reconstructions \\
Technique \\
Expander separated from in vivo drain contact \\
Subdermal tunnelling of the drain \\
Alloderm* sling interface between drain and expander \\
Mupirocin cream to drain site until drain removed and site healed \\
Drain removal after 1 week \\
Follow-up 8 weeks \\
Common operative techniques for both series \\
Chlorhexidine chest bath preoperatively \\
Standard sterile technique and preoperative antibiotics \\
Bacitracin and kanamycin containing irrigating saline \\
No skin touch of expander \\
Partial submuscular expander placement \\
Oral postoperative prophylactic antibiotics until drain out and drain site \\
healed \\
Expander port access in clinic using strict sterile technique \\
* LifeCell Corporation, USA
\end{tabular}

entrance at the lateral inframammary fold and then draped over the inferior Alloderm and the more superior pectoralis major muscle, both providing complete coverage of the expander. Doing so avoided any drain contact with the expander. In contrast to the first series, all 23 reconstructions in this second series received mupirocin $2 \%$ cream to the drain site three times per day. Additionally, in the second series, all drains were removed at the end of the first postoperative week, regardless of drain output volume, whereas in the first series, drains were removed when output was less than $25 \mathrm{~mL}$ for two days (Table 1).

\section{Postoperative evaluation}

All patients were instructed to keep drain sites dry from water and continue prophylactic oral antibiotics until the drains were removed. All patients were followed closely over the first eight postoperative weeks. 'Expander breast infection' was defined as typical clinical evidence of infection of the breast with or without positive cultures from the periprosthetic fluid or the expander itself. In the event of breast infection, the expander was removed after a failed one to two week course of broadspectrum oral antibiotics. Statistical analysis involved the proportionate comparison of risk factors for infection between those women that developed infection in the first series compared with all women in the second series. Additionally, proportionate comparison statistics analyzed the incidence of infection between the first and second series.

\section{RESULTS}

In 139 consecutive women, 200 first-stage expander breast reconstructions were completed. The same surgeon (JDM) completed all first-stage expander breast reconstructions with a follow-up of eight weeks. Risk factors for infection identified in
TABLE 2

Patient-related risk factors for infection in each series

\begin{tabular}{|c|c|c|c|c|}
\hline Patient & Obesity & Smoking & Diabetes & Chemotherapy \\
\hline \multicolumn{5}{|c|}{ Series 1 (for those women who developed infection) } \\
\hline 1 & & & & Yes \\
\hline 2 & Yes & Yes & & \\
\hline 3 & & & & Yes \\
\hline 4 & & & & Yes \\
\hline 5 & Yes & & Yes & \\
\hline 6 & Yes & & Yes & \\
\hline 7 & Yes & & & Yes \\
\hline 8 & & Yes & & \\
\hline \multicolumn{5}{|l|}{9 none } \\
\hline 10 & & & & Yes \\
\hline \multicolumn{5}{|c|}{ Series 2 (all women) } \\
\hline 1 & & Yes & & \\
\hline 2 & & Yes & & Yes \\
\hline 3 & Yes & & & \\
\hline \multicolumn{5}{|l|}{4 none } \\
\hline 5 & & Yes & & Yes \\
\hline \multicolumn{5}{|l|}{6 none } \\
\hline 7 & & Yes & & Yes \\
\hline 8 & & & & Yes \\
\hline \multicolumn{5}{|l|}{9 none } \\
\hline 10 & Yes & & & Yes \\
\hline 11 & & Yes & & Yes \\
\hline \multicolumn{5}{|l|}{12 none } \\
\hline 13 & & Yes & & Yes \\
\hline 14 & & & & Yes \\
\hline 15 & Yes & & & Yes \\
\hline 16 & & & & Yes \\
\hline 17 & & Yes & & \\
\hline 18 & Yes & & & \\
\hline
\end{tabular}

this study included obesity, current history of smoking, diabetes, and the use of neoadjuvant or adjuvant chemotherapy. The patients in the first series of reconstructions that developed infection (10 women) and all patients in the second reconstructive series (18 women) shared the statistically same level of aggregate risk factors $(\mathrm{P}=0.531)$ for the development of infection (Table 2). The patients in the first series who did not develop infection shared a lower level of aggregate risk factors than those patients in series 2. However, the patients in the second series, the series that included the addition of in vivo seclusion of the percutaneous drain from the expander, the use of mupirocin cream to the drain site and removal of the drain at one week, displayed a statistically decreased rate of infection when compared with those patients in first series, which did not incorporate these measures $(\mathrm{P}=0.001$, Table 3$)$. On average, drains were removed 20 days postoperatively for the first series and 7.5 days postoperatively for the second series.

Further analysis of infection patterns were elucidated through the first series. All infections, which only occurred in the first series in 10 of 177 breasts, required expander explantation for infection clearance. Additionally, four women in the first series who had undergone bilateral expander reconstruction developed infection, although in each case only one breast became infected. Through internal review, radiation therapy was not a statistically significant risk factor for the development of infection although chemotherapy was positively correlated as 
TABLE 3

\section{Infection incidence for both series}

\begin{tabular}{ll}
\hline Series $\mathbf{1}$ & \multicolumn{1}{c}{ Series $\mathbf{2}$} \\
\hline 177 reconstructions & 23 reconstructions \\
10 infections & 0 infections \\
$5.65 \%$ & $0 \%$ \\
\hline
\end{tabular}

$60 \%$ of women (six of 10) developing infection had begun chemotherapy when the infection was diagnosed. On average, infection was clinically diagnosed 38 days after expander placement while the drain had already been removed 18 days before the diagnosis of infection. All breasts had the drain removed before the diagnosis of infection. At the time of explantation of the 10 infected expanders, the expanders and periprosthetic fluid were sent for culture. All cultures of the infected expanders were positive while all cultures of all periprosthetic fluids were negative. Organisms isolated included methicillin-resistant Staphylococcus aureus (five infections of 10), methicillinsusceptible $S$ aureus (three of 10), Acinetobacter species (one of 10) and Enterobacter cloacae (one of 10).

\section{DISCUSSION}

Two-stage expander breast reconstruction remains a popular reconstructive option, especially in cases of planned adjuvant radiation therapy or when autologous techniques are not adequate or possible. However, when compared with solely autologous breast reconstruction, eradication of infection in expander breast reconstruction proves more difficult, leading to the most frequent reason for premature expander removal, as supported in large studies (1-3). Doing so then challenges secondary reconstructive efforts and may add further cause for patient depression and disappointment (4), and offers further health care financial burden (5). While the principle cause for expander breast infection is difficult to define in each case, non-surgeon-related leading risk factors for surgical site infection and breast infection have been well elucidated and include age, BMI, radiation therapy, chronic obstructive pulmonary disease, axillary lymph node dissection, tumour stage, diabetes, tobacco use, previous breast scars, mastectomy flap necrosis, hematoma and seroma $(6,7)$. Because single-surgeon-related factors were controlled throughout the present study, patientrelated risk factors, many of which are uncontrollable given the relatively short interval between cancer diagnosis and mastectomy, were defined as obesity (BMI greater than $30 \mathrm{~kg} / \mathrm{m}^{2}$ ), current smoking, diabetes, and the use of preoperative or postoperative chemotherapy. Controllable patient variables, such as supplemental oxygen, maintenance of core body temperature and strict management of blood sugar, have been shown to be effective in reducing surgical site infection and were likewise controlled in the present study (8).

Because the fate for infection of the undrained surgical wound may be sealed at the time of incision closure, we examined the drain as a risk factor for surgical site infection. In the presemt study, in women who had undergone bilateral expander reconstruction and developed infection (four women), only one breast in each case developed infection. Although this subseries is small, if intraoperative contamination were to significantly occur, both surgical sites should reliably be exposed to the same contamination risk, more reliably leading to bilateral infection (not to just one breast). The drain could impose differential risk for infection between each breast. The literature is replete from across many surgical specialties regarding infection and its relationship to the use of closed suction drains; the majority of the referenced studies identified an increased risk of related infection, while the balance of these studies showed a lower risk of infection, or no statistical difference in infection with or without drains (DE Fry, personal communication; 6,7,9-17). Understandably, multivariate risk factors make it difficult to support the strength of a unique risk factor. However, it has been shown that a percutaneous closed suction drain becomes bacterially colonized, often within $24 \mathrm{~h}$ postoperatively (DE Fry, personal communication). It has also been shown that bacteria migrate retrograde within the closed suction drain tubing above the antireflux valve (14), as well as along the drain tract at the skin level with high frequency (18). Additionally, the rate of migration of organisms seems to be proportional to the extent of contamination (14). However, in one orthopedic study, drain bulb cultures did not always predict infection risk. Culture positivity at the level of the internal drain tip predicted wound infection in 50\% of cases while a negative tip culture virtually excluded deep infection (19). Hence, it would stand to reason that ascending bacteria could, potentially, colonize a relatively large prosthetic device, such as a breast expander, to such a degree to eventually overwhelm local in vivo defenses, leading to clinical infection (20). Compared with mastectomy alone, women undergoing mastectomy with immediate expander placement share additional risk factors for infection, such as longer operative time $(21,22)$ with more extensive tissue dissection and devitalization. In one series (23), the incidence of surgical site infection for expander reconstruction has been shown to be nearly three times that of mastectomy alone ( $12.4 \%$ versus $4.4 \%$ ), although the infection risk of expander and implant breast reconstruction may range from $1 \%$ to $24 \%$ (24). Although not found to be statistically significant in our study, radiation therapy has been shown to increase the incidence of breast implant infection (24) while yet other studies do not show this increased incidence (25). With leading risk factors otherwise controlled, we then examined the potential benefit of in vivo separation of the drain in first-stage expander breast reconstruction.

Based on germ theory principles of infection, the addition of a drain advances a 'clean' operative case to a 'clean-contaminated' postoperative case. The drain protocol used in the last 23 reconstructions introduced technically and financially feasible techniques to decrease postoperative exposure of bacteria to the expander. The topical use of antibiotic ointment $(26,27)$ and preoperative chlorhexidine bathing have been shown to effectively reduce $S$ aureus colonization, with low rates of resistance formation (Dr Robert Rapp, personal communication; 21,26,28,29). Additionally, effective hand washing by patients and care takers in the hospital and at home greatly decreases cross-infection and infection risk $(30,31)$. The early removal of the drain eliminates further retrograde bacterial migration while continued use of prophylactic antibiotics until the drain is removed and the skin healed, as was continued in the present study, has historically shown to be of benefit even in very large series (32).

Though further research is needed, the benefits of drain and expander separation by the use of drain subdermal tunnelling 
or by the use of an intervening acellular dermal matrix may prove to be the strongest risk reduction factor for the development of expander infection. Circumferential exposure of the subdermal colonized drain to healthy subcutaneous tissue may help eradicate bacteria outside the in vivo drain. The rapid revascularization of acellular dermal matrix may perform a similar function. As has been shown in large infected operative fields, human regenerative acellular dermal matrix revascularizes quickly while maintaining strength and integrity (33). In our study, Alloderm was used in patients in whom the subcutaneous fatty tissues were not thick enough to reliably separate the drain from the expander.

Clearance of infection with an expander in place can prove difficult or, as seen in the present study, impossible. In the present study, oral antibiotics seemed to control the infection, but did not cure it completely. While percutaneous aspirates of the periprosthetic fluid proved to be sterile in all infected cases, the expanders were culture-positive in each case. The clinical diagnosis of infection led to early explantation. However, the diagnosis was clearly delayed by an average 18 days, possibly due to the characteristics of the micro-organism. Diagnosis of infection of a prosthesis may prove difficult due to a biofilm produced by the organism, 'shielding' the organism and expander from the soft tissues, thus delaying diagnosis (20). New biomaterials with more potent antimicrobials to penetrate these biofilms and eradicate organisms are needed (20).

\section{CONCLUSIONS}

The present study found that percutaneous closed suction drains do serve as an increased risk for expander infection. However, although we will continue to accrue data, early results indicate that in vivo protection of the expander with Alloderm or subdermal tunnelling, topical antibiotic ointment use and early drain removal may significantly reduce expander infection.

DISCLAIMER: The senior author (JDM) is the only listed author for this study to use the mupirocin ointment or cream or to discontinue the percutaneous drains as discussed in this study.

\section{REFERENCES}

1. Disa JJ, Ad-El DD, Cohen SM, Cordeiro PG, Hidalgo DA. The premature removal of tissue expanders in breast reconstruction. Plast Reconstr Surg 1999;104:1662-5.

2. Spear SL, Majidian A. Immediate breast reconstruction in two stages using textured, integrated-valve tissue expanders and breast implants: a retrospective review of 171 consecutive breast reconstructions from 1989 to 1996. Plast Reconstr Surg 1998;101:53-63.

3. Cordeiro PG, McCarthy CM. A single surgeon's 12-year experience with tissue expander/implant breast reconstruction: Part II. An analysis of long-term complications, aesthetic outcomes, and patient satisfaction. Plast Reconstr Surg 2006;118:832-9.

4. Hoffman E. Prophylactic antibiotic usage in clean surgical procedures. Am Surg 1984;50:161-4.

5. Anderson DJ, Kirkland KB, Kaye KS, et al. Underresourced hospital infection control and prevention programs: Penny wise, pound foolish? Infect Control Hosp Epidemiol 2007;28:767-73.

6. Drapeau CM, D'Aniello C, Brafa A, et al. Surgical site infections in plastic surgery: An Italian multicenter study. J Surg Res 2007;143:393-7.

7. Rubin RH. Surgical wound infection: Epidemiology, pathogenesis, diagnosis and management. BMC Infect Dis 2006;6:171.

8. Fry DE, Fry RV. Surgical site infection: The host factor. AORN J 2007;86:801-10.

9. Magee C, Rodeheaver GT, Golden GT, Fox J, Edgerton MT, Edlich RF. Potentiation of wound infection by surgical drains. Am J Surg 1976;131:547-9.

10. Goonatilake PC. Postoperative wound infection: Application of multiple regression analysis to patients parameters. Int J Biomed Comput 1981;12:393-9.

11. Araco A, Gravante G, Araco F, Delogu D, Cervelli V, Walgenbach K. Infections of breast implants in aesthetic breast augmentations: A single-center review of 3,002 patients. 2007;31:325-9.

12. Parker MJ, Roberts C. Closed suction surgical wound drainage after orthopaedic surgery. Cochrane Database Syst Rev 2001;(4):CD001825. Update in: Cochrane Database Syst Rev 2007;(3):CD001825.

13. McCarthy CM, Disa JJ, Pusic AL, Mehrara BJ, Cordeiro PG. The effect of closed-suction drains on the incidence of local wound complications following tissue expander/implant reconstruction: a cohort study. Plast Reconstr Surg 2007;119:2018-22.

14. Moss JP. Historical and current perspectives on surgical drainage. Surg Gynecol Obstet 1981;152:517-27.

15. Scevola S, Youssef A, Kroll SS, Langstein H. Drains and seromas in TRAM flap breast reconstruction. Ann Plast Surg 2002;48:511-4.

16. Rey JE, Gardner SM, Cushing RD. Determinants of surgical site infection after breast biopsy. Am J Infect Control 2005;33:126-9.

17. Lilani SP, Jangale N, Chowdhary A, Daver GB. Surgical site infection in clean and clean-contaminated cases. Indian J Med Microbiol 2005;23:249-52.

18. Raves JJ, Slifkin M, Diamond DL. A bacteriologic study comparing closed suction and simple conduit drainage. Am J Surg 1984;148:618-20.

19. Sankar B, Ray P, Rai J. Suction drain tip culture in orthopaedic surgery: A prospective study of 214 clean operations. Int Orthop 2004:28:311-4.

20. Reid G. Bacterial colonization of prosthetic devices and measures to prevent infection. New Horiz 1998;6(2 Suppl):S58-63.

21. Nichols RL. Techniques known to prevent post-operative wound infection. Infect Control 1982;3:34-7.

22. Rey JE, Gardner SM, Cushing RD. Determinants of surgical site infection after breast biopsy. Am J Infect Control 2005;33:126-9.

23. Olsen MA, Chu-Ongsakul S, Brandt KE, Dietz JR, Mayfield J, Fraser VJ. Hospital-associated costs due to surgical site infection after breast surgery. Arch Surg 2008;143:53-60.

24. Nahabedian MY, Tsangaris T, Momen B, Manson PN. Infectious complications following breast reconstruction with expanders and implants. Plast Reconstr Surg 2003;112:467-76.

25. Yii NW, Khoo CT. Salvage of infected expander prostheses in breast reconstruction. Plast Reconstr Surg 2003;111:1087-92.

26. Ridenour G, Lampen R, Federspiel J, Kritchevsky S, Wong E, Climo M. Selective use of intranasal mupirocin and chlorhexidine bathing and the incidence of methicillin-resistant Staphylococcus aureus colonization and infection among intensive care unit patients. Infect Control Hosp Epidemiol 2007;28:1155-61.

27. Zinner SH, Denny-Brown BC, Braun P, Burke JP, Toala P, Kass EH. Risk of infection with intravenous indwelling catheters: Effect of application of antibiotic ointment. J Infect Dis 1969;120:616-9

28. Diekema DJ, Climo M. Preventing MRSA infections: Finding it is not enough - comment. JAMA 2008;299:1190-2.

29. .Nichols RL. Preventing surgical site infections: A surgeon's perspective. Emerg Infect Dis 2001;7:220-4.

30. Boyce JM, Pittet D; Healthcare Infection Control Practices Advisory Committee. Society for Healthcare Epidemiology of America. Association for Professionals in Infection Control. Infectious Diseases Society of America. Hand Hygiene Task Force. Guideline for Hand Hygiene in Health-Care Settings: recommendations of the Healthcare Infection Control Practices Advisory Committee and the HICPAC/SHEA/APIC/IDSA Hand Hygiene Task Force. Infect Control Hosp Epidemiol 2002;23(12 Suppl):S3-40.

31. Pittet D, Stéphan F, Hugonnet S, Akakpo C, Souweine B, Clergue F. Hand-cleansing during postanesthesia care - comment. Anesthesiology 2003;99:530-5.

32. Hoffman E. Prophylactic antibiotic usage in clean surgical procedures. Am Surg 1984;50:161-4.

33. Butler CE, Langstein HN, Kronowitz SJ. Pelvic, abdominal, and chest wall reconstruction with AlloDerm in patients at increased risk for mesh-related complications. Plast Reconstr Surg 2005;116:1263-75. 